\title{
Immediate repeat of a septic shock simulation: Nursing students' lived experience
}

\author{
Mary Beth R. Maguire, Anne White \\ WellStar School of Nursing, Kennesaw State University, Kennesaw, GA, USA
}

Received: March 26, 2021

Accepted: April 19, 2021

Online Published: April 28, 2021

DOI: $10.5430 /$ jnep.v11n9p9

URL: https://doi.org/10.5430/jnep.v11n9p9

\begin{abstract}
Background and objective: The COVID-19 pandemic has placed a significant increase for the need of high quality, high fidelity simulation practices to replace limited clinical experiences. Repetitive experiential practice is a training strategy used among professionals to bridge theoretical concepts to action. Furthermore, immediate repetitive experiential practice in a simulation environment is a novel approach that holds promise for learners to improve their response to critical conditions through increased faculty guided reflection. This study aimed to explore student attitudes regarding an immediate repeat of a simulation as a first step to explore training effectiveness.

Methods: Students enrolled in a complex health baccalaureate nursing course participated in an immediate repeat of a septic shock simulation. An interpretive phenomenological approach was utilized to better understand undergraduate nursing students' lived experience of learning through a repeat septic shock simulation.

Results: Three themes emerged: Appreciation of Knowledge, Awareness of Skill, and Awareness of Attitudes.

Conclusions: Learners found an immediate repeat of the simulation a valuable teaching strategy. Participants described a growing sense of differentiating priorities when managing a patient in septic shock. The immediate repeat simulation was deemed impactful to the learners' knowledge, skills, and attitudes. This is a viable option for educators to incorporate at a time when forced to utilize simulation experiences to replace limited clinical opportunities.
\end{abstract}

Key Words: Repeat, Simulation, Septic shock, Nursing student, Qualitative

\section{INTRODUCTION}

The chaos of the COVID-19 pandemic impacted the usual training of student nurses. ${ }^{[1]}$ Educators were forced to rely on the simulated environment to replace limited clinical experiences. Repetitive experiential practice is a training strategy used among professionals to bridge theoretical concepts to action. $^{[2]}$ Airline pilots, astronauts, and the military frequently rehearse complex skills in a simulated environment to improve performance. ${ }^{[3-5]}$ Nursing students also rehearse the execution of complex tasks in simulation; ${ }^{[6,7]}$ however, only one study describes the effect of nursing students imme- diately repeating a scenario to improve performance. ${ }^{[8]}$ The impact of immediate repetitive experiential practice on the affective domain of nursing students in a simulated learning environment is novel and underreported. Due to the novel nature of the simulation design, an exploration of participants' attitudes should be investigated as a first-level assessment. ${ }^{[9]}$ Immediate repetitive experiential practice may enhance nursing students' attitudes towards managing complex, high-risk conditions such as septic shock to improve patient outcomes. Several themes are prevalent in the literature supporting repetitive experiential practice with undergraduate nursing

\footnotetext{
*Correspondence: Mary Beth R. Maguire; Email: mmaguir5@kennesaw.edu; Address: WellStar School of Nursing, Kennesaw State University, Kennesaw, GA, USA.
} 
students in simulation. The themes include repetitive experiential practice, initiatives to improve septic shock survival, and simulation's overall effect on student attitudes.

\subsection{Immediate repetitive experiential practice}

Repetitive experiential practice allows learners opportunities to enhance performance through an increased sense of salience. Such an approach provides an occasion to correct errors by refining competencies to make skills automatic and effortless. ${ }^{[10]}$ Simulation based learning allows for repetitive experiential practice under the guidance of an expert facilitator. ${ }^{[11]}$ This expert-led guidance provides a means to grasp the narrative understanding of a particular clinical situation through both group and individual reflection. ${ }^{[12]}$ This narrative understanding results in a greater sense of salience thus, moving students along the continuum of developing clinical reasoning. It is, therefore, necessary to include repetitive elements during training. However, the effects of immediate repetitive practice are underreported.

\subsection{Initiatives to improve septic shock survival}

Improved performance through repetitive practice holds promise to improve septic shock patient outcomes. Sepsis is a medical emergency caused by a dysregulated response to infection. ${ }^{[13]}$ Nearly 270,000 American deaths are reported annually due to sepsis. ${ }^{[14]}$ International initiatives such as

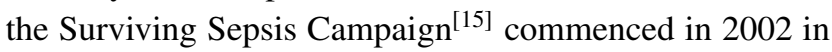
response to the high morbidity and mortality of sepsis. Similar initiatives include improved clinical decision support systems, ${ }^{[16]}$ screening tools, ${ }^{[17]}$ and sepsis care bundles. ${ }^{[18]}$ Students must have opportunities to rehearse sepsis scenarios to effectively prepare undergraduate nursing students to identify and respond to a patient in sepsis. Clinical simulation provides an excellent strategy for repetitive practice in a safe learning environment.

\subsection{Simulation effect on student attitudes}

Several studies support nursing students' affinity to clinical simulation. Dame and Hoebeke ${ }^{[19]}$ report more positive undergraduate nursing student attitudes regarding caring for dying patients after participation in an end-of-life simulation $(p<.001)$. Students participating in an interprofessional simulation of nursing, athletic training, and occupational therapy students also report improved attitudes toward other professions after learning with and from each other during simulation. ${ }^{[20]}$ Additionally, simulation is an effective strategy to improve nursing students' attitudes on poverty ${ }^{[21]}$ and quality improvement practices. ${ }^{[22]}$ Exploring students' attitudes regarding simulation learning events is an International Nursing Association for Clinical Simulation and Learning (INACSL) best-practice standard for quality improvement. ${ }^{[11]}$
There is no literature exploring student attitudes of their experience in an immediate repeat of a simulation.

\subsection{Aim}

The aim of this study is to explore the lived experience of learning through a repeat septic shock simulation. Such study is important as little research to date has focused on students' attitudes. Attitudes of learning through a repeated septic shock simulation can translate to better patient outcomes and improved nursing competency when caring for this complex clinical situation.

\section{Methods}

\subsection{Description of learning event}

The researchers used an interpretive phenomenology approach to identify themes and descriptions to understand better undergraduate nursing students' lived experience of learning through a repeat septic shock simulation. This approach allowed researchers to explore the shared experiences as subjectively experienced. Approval for the study was obtained through the university's Institutional Review Board. Students enrolled in the adult health nursing course during two consecutive semesters participated in the learning experience. Data analyzed included only responses from students who consented to the study.

The learning event included a one-hour didactic session related to the management of a patient in septic shock. Following the didactic instruction, participants attended a highfidelity simulation scenario incorporating simulation standards from the INACSL Standards Committee. ${ }^{[11]}$ A certified healthcare simulation educator created the scenario. The researchers randomly assigned learning groups of up to six students as the assessment nurse, medication nurse, documentation nurse, and the remaining students as participantobservers. Immediately following the simulation, the learning group was led through a structured debrief by a faculty member trained in INACSL debriefing best practice standards. ${ }^{[11]}$ Upon the conclusion of the debrief, the same learning group returned to the simulation suite to repeat the scenario with learners assigned to the identical roles as the first simulation. Once the second simulation was complete, the learning group remained in the simulation suite for a second debrief by the same faculty member.

After the second debrief, participants completed an online survey. The descriptive qualitative research design used an open-ended survey method (see Table 1). Questions were broad, allowing the participants to tell their stories and recount their experiences without restricting those experiences' descriptions. Unique codes for each participant's survey were assigned after deleting personal identifiers. 
Table 1. Survey questions

1) How did you feel during the first simulation?

2) What factors influenced your performance in the first simulation?

3) In what ways could you have handled the first scenario better?

4) How did you feel during the second simulation?

5) What factors influenced your performance in the second simulation?

6) How did the opportunity to redo (repeat) the scenario change your attitude about the process of treating a patient in septic shock?

7) What aspects of the simulation experiences helped change what you know about septic shock?

\subsection{Informants}

Informants in the study consisted of ninety-seven $(n=97)$ baccalaureate nursing students enrolled in the course during two semesters. Eighty-six (88.7\%) were female and 11 were male $(11.3 \%)$. The age range of the participants was $21-52$ years. No further demographic data was collected.

\subsection{Data analysis}

The data were analyzed hermeneutically using guidelines proposed by Diekelmann and Allen ${ }^{[23]}$ to interpret commonalities in the meanings of the lived experience. Two researchers collaborated using a qualitative data analysis software, Atlas.ti 8 (Scientific Software Development, Corvallis, Oregon), to develop the major descriptive coding categories. Multiple research team meetings were held to review codes and continued until resolution of differences in coding agreement was reached. Then, identification of subcategories that reflected narrower topical areas within the major codes emerged. Finally, the researchers used the codes to generate the themes with supporting excerpts to reach a sense of the participants' overall story.

\subsection{Methodological rigor}

The researchers used the trustworthiness criteria (dependability, transferability, confirmability, and credibility) described by Guba and Lincoln ${ }^{[24]}$ to achieve methodological rigor. The researchers used journaling and a detailed audit trail during the analysis process to achieve dependability and confirmability. The detailed description of the students' perception of the learning strategy allowed educators to evaluate the data's application and transferability. Credibility was ensured by peer debriefing between members of the research team during the data analysis process.

\section{RESUlts}

The study of undergraduate nursing students' lived experience of learning through a repeat septic shock simulation led to the emergence of three main themes: Appreciation of Knowledge, Awareness of Skill, and Awareness of Attitudes.

\subsection{Appreciation of knowledge}

An appreciation of knowledge was identified by participants. Four subthemes were described. The themes were: Simulation Helps to Solidify Knowledge, Repeat Simulation Helps to Practice/Rehearse/Prioritize/Visualize, Knowing Future Success is Possible, and the Value of Debrief.

\subsubsection{Repeat simulation helps to solidify knowledge}

Stories of the appreciation of knowledge gained through a repeat simulation and debrief focused on the importance of simulation in solidifying the participants' and observers' knowledge about septic shock. It also allowed the participants to apply the information in a safe environment. One student indicated:

I loved the fact that we got to redo (repeat) the scenario. Typically, after sim, I feel like I learned something, but that it is all going to fly out of my head because I didn't get to solidify my learning experience. This time not only did I get hands on experiences about how to do something correctly, but it also helped my confidence a ton. Instead of going home feeling like I messed everything up, I'm going home feeling like I made mistakes, but successfully learned from them.

Another student expressed similar feelings, "I think the redo (repeat) solidifies what should be done and what should not be done in this scenario in the students' minds. I think getting to re-do (repeat) the simulation was a great learning experience". Yet another student added that, "Participating in the simulation helped me to see how the septic shock progressed on the patient. It felt a lot different than reading the textbook about the septic shock".

The students talked about the importance of having the opportunity to correct their mistakes during the repeat. Expressing it helped them recognize and apply the steps in the sepsis protocols, thus increasing retention of knowledge. One stated: "Sepsis is a process with a progression that can be addressed with protocols provided. To this point sepsis has 
always seemed nebulous, but today it seemed critical, but manageable". Another described the experience as:

I felt more confident in recognizing the steps needed throughout the treatment. I also felt more knowledgeable of the specific information needed for calling the MD (physician) and proceeding then on with the treatment. This is a great experience to correct mistakes, which makes the knowledge gained last longer.

\subsubsection{Repeat simulation helps to practice/rehearse/ prioritize/visualize}

The repeat simulation allowed the students to practice, rehearse, learn to prioritize, and finally visualize the simulation's unfolding scenario. All of these are essential aspects when caring for a deteriorating patient. One student indicated they were "able to prioritize nursing actions." While another student felt that:

I began to visualize and understand the stepwise approach to treating septic shock. The sepsis care bundles are extremely beneficial to follow because they are based on evidence and help during intense moments. I feel much more confident following the second scenario compared to my initial feelings of nervousness, and this is because we were able to redo (repeat) the simulation.

Another student described, "Having the second round of simulation helped me reprioritize the interventions to promote the best outcome for the patient." One spoke of, "Knowing what to prioritize and when, for example the antibiotics and the fluids, and the importance of continuous vital signs when the patient is deteriorating." Another added, "The second simulation seemed to run much smoother, everyone was more relaxed and able to think with a clear head. The medications were prioritized, and the patient was assessed quickly."

\subsubsection{Knowing future success is possible}

Stories from students concerning their confidence in caring for a septic shock patient in the future were shared. The students verbalized how applying what they learned in a safe environment was significant. One student described her experience:

This is the first simulation where we have got to repeat the simulation and I think that it is beneficial because there is an opportunity for redemption. It also gives us the opportunity to better grasp the diagnosis we are treating.
Another added, "The opportunity to make mistakes on a non-human entity allows us to help further our nursing skills without harming an actual person". This idea was also supported by a student who responded,

Simulation was very helpful. It allowed us to take what we've learned in class and actually apply it to the real world even if it is not a real person, you still feel that same panic as if it was a real person. It allowed me to better recognize signs and symptoms of shock.

A student skeptical of a repeat simulation added, "I didn't think repeating the same simulation would be helpful, but I definitely felt more comfortable doing so and think I'll be more comfortable when I experience septic shock in the real world."

\subsubsection{The value of debrief}

The debrief allowed the participants to rehearse and gain confidence in their abilities to re-enter the simulation with a better understanding of a septic shock patient's care. One student expressed, "the debrief after the first simulation guided me to improve my performance in the second scenario." Another student added, "The feedback we got after the first round definitely changed my thinking and my actions." One participant described the value of being able to repeat the simulation after reflecting during the debrief, stating that:

We had already gotten feedback on mistakes that were made, so we were able to focus on the mistakes and do our best to correct them. This was still difficult, but at least we had an idea of our weaknesses and what we did well to know where to focus our energy.

\subsection{Awareness of skill}

Awareness of skill was the second theme to surface in the students' descriptions of a septic shock repeat simulation. The three subthemes that emerged in the description of the student's stories related to the awareness of skill gained included: Transition of Skills to Practice, Recognition and Action, and Value of Working in a Team.

\subsubsection{Transition of skills to practice}

As the students looked to their future career in nursing and the reality of assuming care for a patient in septic shock, they expressed gratitude for the learning experience. Students said that the experience increased both their confidence and competence:

I felt more confident. If I faced my first patient in shock while in a clinical setting with real people, I may not look as competent, but having 
this experience gave me practice for what I will see in my future career.

Another participant added:

I feel more confident in being able to intervene quickly and move faster. I haven't had much experience with an emergency or critical situation, .... this simulation allowed me to learn more and feel more confident for when I start my nursing career.

The learning experience allowed students to reflect on areas needing improvement before they transitioned to practice. One recognized:

I think it made me realize that with the knowledge of what to do for a patient in septic shock, it isn't quite as intimidating. As now I feel like I have a decent idea of what to look for and expect. Now, I just need to work on ensuring I am familiar with the equipment to ensure that next time in real life I can implement the interventions quickly and smoothly.

\subsubsection{Recognition and action}

The simulation caused the students to reflect on the immediacy of caring for a deteriorating patient in septic shock. Students became aware of the importance of a timely assessment and knowledge specific to appropriate intervention or action on the patient's behalf. One student described the simulation as showing, ".... how quickly a patient can go downhill." Several other participants reiterated the urgency and added the need for the nurse's efficiency. One felt, "I realized that things could take a quick turn, so it is urgent that as the nurse to be as efficient, timely, and careful as possible." Another described it as, "It allowed me to see how delicate these patients are, and you must react quickly but still understanding what you are doing for the patient. It also allowed for a better outcome and it made me feel more prepared to treat a septic patient or to recognize signs and symptoms."

\subsubsection{Value of working in team}

Student's awareness of the importance of teamwork and pulling from each other's strengths was highlighted as one of the benefits of the repeat simulation. One student expressed that, "...during simulation, I learned how to more effectively communicate with other team members and physicians." Another added, "This simulation also showed the importance of teamwork and pulling from each other's strengths."

Published by Sciedu Press
Students valued teamwork as they learned from their mistakes and helped prepare them for their future in nursing. One commented:

Completing a redo (repeat) scenario provided me and my team with the opportunity to directly learn from our mistakes, immediately correct the mistakes and see how the scenario would play out with those new decisions. The second scenario allowed me to feel more confident in my nursing ability and provided me with an immediate opportunity to learn from my mistakes.

\subsection{Awareness of attitudes}

A third theme to emerge was an awareness of attitudes related to the repeated simulation. A variety of strong emotions were described. Three subthemes regarding attitudes surfaced: Sense of Anxiety, Move Towards Confidence, Simultaneous Experience of Anxiety and Confidence.

\subsubsection{Sense of anxiety}

Participants frequently reported a sense of anxiety in response to participating in the first simulation. One student commented, "I was nervous because I have never encountered a patient with sepsis." The sense of anxiety was also described by another participant as, "I felt nervous and uncertain of how to handle the scenario."

\subsubsection{Move towards confidence}

The transition from nervousness to confidence was frequently described when participants reflected on the feelings related to the repeat simulation. One student stated, "I felt more confident in what needed to be done...". Another participant described the confidence that emerged as:

I felt prepared, competent, and like I knew how to help this patient. I also felt more confident that some of my inclinations that I did not act upon during the first simulation were correct, so it gave me more confidence as a nurse in general to act on my hunches this time around.

Students who experienced the simulation in the observer role also reported improved confidence after the second simulation. One observer stated,

I felt more confident in both my abilities as an observer, and of my classmates to complete the simulation. I found myself noticing more details I had missed in the first scenario. In fact, I noticed more positive skills done by the nurses. 


\subsubsection{Simultaneous experience of anxiety and confidence}

Participants in the repeat septic shock simulation describe simultaneous feelings of anxiety and confidence. A student expressed feelings during the repeat simulation as, “...still pretty nervous, but I felt like I came in knowing what was going to happen so I thought I would do well." The concurrent emotions were echoed from another participant who stated, "I am always affected by nervousness, but my teammates were extremely helpful, and worked together really well."

\section{Discussion}

The lived experience of learning through a repeat septic shock simulation among undergraduate nursing students revealed several important themes that make a repeat simulation opportunity worth pursuing. Evidence emerged that undergraduate nursing students knew the knowledge needed to care for a patient in septic shock after participating in a repeat simulation. Additionally, students acknowledge a noticeable improvement of their skills required to intervene in an emergency. Finally, the participants also described an awareness of several positive reactions toward managing a patient in septic shock.

\subsection{Solidify knowledge}

Repetitive experiential practice helped solidify knowledge. Nurse educators frequently rely on examinations that focus on recall and may or may not include the practical application of septic shock protocols to evaluate students' abilities. Findings from this study suggest the opportunity to mentally rehearse during debrief the proper sequence of actions and then immediately apply the knowledge in a patient care situation is appreciated by undergraduate nursing students. This positive reinforcement of knowledge is recognized as valuable to learners.

\subsection{Awareness of skills}

Sepsis Data on surviving sepsis ${ }^{[25]}$ reflects the importance of early assessment and intervention to improve patient outcomes. This study demonstrates that undergraduate nursing students appreciate the opportunity to apply the needed skills in a simulated environment. Participants also valued the urgency that surrounds a patient in septic shock. The students realized the time-sensitivity of the clinical situation and their actions through the back-to-back scenarios. While learners knew the patient would decompensate, they appreciated the uniqueness this study afforded them to perform skills in realtime, immediately following debrief. These findings support previous studies focused on critical patient scenarios that found repetitive practice improves performance. ${ }^{[26-28]}$

\subsection{Positive reactions}

The significance of undergraduate nursing students' attitudes regarding a repeat simulation provides meaningful information. First, positive attitudes related to the repeat simulation reflect the fidelity of the scenario. This reflection confirms the event's reality to adequately prepare students to manage the situation in actual patient encounters. These results are like other studies and suggest simulation-based education's effectiveness is related to increased reflection time. ${ }^{[6,29,30]}$ The immediate repeat of the simulation resulted in two faculty facilitated debrief sessions thus creating greater support and reflection time. Second, simulation standards ${ }^{[11]}$ call for educators to evaluate the effectiveness of scenarios. Therefore, it is imperative to assess attitudes related to a repeat simulation to understand the complex emotions that may emerge. By exploring the students' attitudes regarding an immediate repeat septic shock simulation evidence emerged that they were able to identify improvement in their knowledge and performance.

\subsection{Limitations}

Several study limitations make generalization of findings difficult. First, the small sample size makes translation to the larger population of undergraduate nursing students difficult. Second, the study was isolated to a single site. Third, the repeated simulation was a septic shock scenario. It is possible less complex simulation scenarios focused on basic skills and requiring minimal critical thinking may not prove as impactful a learning experience. Future studies should seek to evaluate the effectiveness of a repeat simulation scenario among a larger sample of undergraduate nursing students across multiple schools of nursing. There is also opportunity to explore immediate repeat of a simulation scenario among different types of clinical situations.

\section{Conclusion}

In a time when educators are using simulation to replace actual clinical experiences due to the COVID-19 pandemic, immediate repeat simulation is a viable option. Students found the immediate repeat simulation a worthwhile experience. Whether in the participant role or observer role, respondents valued the learning strategy. This time intensive activity was worthwhile for educators to pursue because participants described improved knowledge, skills, and attitudes toward managing a patient in septic shock. These gains may lead to better prepared graduate nurses who enter practice more equipped to improve patient outcomes.

\section{CONFlicts of InTERest Disclosure}

The authors declare that there is no conflict of interest. 


\section{REFERENCES}

[1] Ulenaers D, Grosemans J, Schrooten W, et al. Clinical placement experience of nursing students during the COVID-19 pandemic: A cross-sectional study. Nurse Education Today. 2021; 99. PMid:33545565 https ://doi.org/10.1016/j.nedt . 2021.10 4746

[2] Montocchio L. Repetitive skill practice: Blending experiential learning \& technology. 2010. Available from: https://trainingindustry.com/articles/learning -technologies/repetitive-skill-practice-blending-e xperiential-learning-technology/

[3] Cook C. Designing a virtual embedded scenario-based military simulation training program using educational design instructional strategies. (Doctoral dissertation, University of Central Florida). Showcase of Text, Archives, Research \& Scholarship. 2018. Available from: https://stars.library.ucf .edu/etd/5854

[4] Everson T, McDermott C, Kain A, et al. Astronaut training using virtual reality in a neutrally buoyant environment. KnE Engineering. 2017; 2(1): 319-327. https://doi.org/10.18502/keg.v $2 i 2.632$

[5] Socha V, Socha L, Szabo S, et al. Training of pilots using flight simulator and its impact on piloting precision. Proceedings of 20th international scientific conference. 2016. Available from: http: //idoaba.eu/567/pub16/lf/174425.pdf

[6] Scoresby J, Shelton BE. Reflective redo from the point of error: Implications for after action review. Simulation \& Gaming. 2014; 45(4-5): 666-96. https ://doi .org/10.1177/1046878114549426

[7] Sivertsen N, McNeill L, Muller A. A redo station after debrief improves learning in undergraduate nursing simulation. Clinical Simulation in Nursing. 2016; 12(11): 469-72. https ://doi .org/10.1 016/j.ecns. 2016.07.007

[8] Maguire MB, White A, Brannan JB, et al. The effect of a repeat septic shock simulation on the knowledge and skill performance of undergraduate nursing students. Journal of Nursing Education and Practice. 2021; 11(1): 30-38. https://doi.org/10.5430/jnep .v11n1p30

[9] Kirkpatrick Partners. The Kirkpatrick model. 2021. Available from: https://www.kirkpatrickpartners.com/Our-Philo sophy/The-Kirkpatrick-Model

[10] Issenberg SB, McGahie WC, Petrusa ER, et al. Features and uses of high-fidelity medical simulations that lead to effective learning: a BEME systematic review. Medical Teaching. 2005; 27(1): 10-28. PMid:16147767 https ://doi.org/10.1080/01421590500046 924

[11] INACSL Standards Committee. INACSL standards of best practice: SimulationSM simulation design. Clinical Simulation in Nursing. 2016; 12(Supplement): 5-12. https://doi .org/10.1016/j .ec ns.2016.09.005

[12] Benner P, Sutphen M, Leonard V, et al. Educating nurses. A call for radical transformation. Jossey-Bass; 2010.

[13] Dantes RB, Epstein L. Combatting sepsis: A public health perspective. Clinical Infectious Diseases. 2018; 67(8): 1300-1302. PMid:29846544 https : //doi.org/10.1093/cid/ciy342

[14] National Center for Disease Control and Prevention. Data and reports, sepsis. 2020. https ://www.cdc.gov/sepsis/datarepor ts/index.html

[15] Society of Critical Care Medicine. About SSC. 2021. https : //www . sccm.org/SurvivingSepsisCampaign/About-SSC
[16] Drahnak DM, Hraynak M, Ren D, et al. Scripting nurse communication to improve sepsis care. Medsurg Nursing. 2016; 25(4): 233.

[17] O'Shaughnessy J, Grzelak M, Dontsova A, et al. Early sepsis identification. MedSurg Nursing. 2017; 26(4): 248-252.

[18] Makic MB, Bridges E. CE: Managing sepsis and septic shock: Current guidelines and definitions. American Journal of Nursing. 2018; 118(2): 34-9. PMid:29329118 https://doi.org/10.1097/01 . N AJ . 0000530223.33211 .f 5

[19] Dame L, Hoebeke R. Effects of a simulation exercise on nursing students' end-of-life care attitudes. Journal of Nursing Education. 2016; 55(12): 701-705. PMid:27893906 https ://doi.org/10.3 928/01484834-20161114-07

[20] Morrell BL, Nichols AM, Voll CA, et al. Care across campus: Athletic training, nursing, and occupational therapy student experiences in an interprofessional simulation. Athletic Training Education Journal. 2018; 13(4): 332-339. https : //doi .org/10.4085/1304332

[21] Menzel N, Willson LH, Doolen J. Effectiveness of a poverty simulation in Second Life $\mathbb{R}$ : Changing nursing student attitudes toward poor people. International Journal of Nursing Education Scholarship 2014; 11(1): 1-7. PMid:24615491 https://doi.org/10.1515/ ijnes-2013-0076

[22] Gaffney MK, Chargualaf KA. Using simulation to improve nursing students' attitudes toward quality improvement. [Poster presentation]. Sigma Theta Tau International/National League for Nursing, Washington, DC, USA. 2020. Available from: https://sigma.nursin grepository.org/handle/10755/20211

[23] Diekelmann N, Allen D. A hermeneutic analysis of the NLN criteria for appraisal of baccalaureate programs. In N. Diekelmann, D. Allen, \& Tanner, C. (Eds.), The NLN criteria for appraisal of baccalaureate programs: A critical hermeneutic analysis. National League for Nursing. 1989; 11-33 p.

[24] Guba EG, Lincoln Y.S. Fourth generation evaluation. Sage; 1989.

[25] Levy MM, Evans LE, Rhodes A. The Surviving Sepsis Campaign Bundle: 2018 update. Intensive Care Medicine. 2018; 44: 925-928. PMid:29675566 https ://doi .org/10.1007/s00134-018-508 5-0

[26] Abe Y, Kawahara C, Yamashina A, et al. Repeated scenario simulation to improve competency in critical care: A new approach for nursing education. American Journal of Critical Care. 2013; 22(1): 33-40. PMid:23283086 https: //doi .org/10.4037/ajcc2013229

[27] Choi EH, Kim EH. Effects of repeated exposure in simulationbased education on hospital emergency care. International Journal of U- and E- Service, Science and Technology. 2016; 9(1): 77-286. https://doi.org/10.14257/ijunesst.2016.9.1.29

[28] Sapiano AB, Sammut R, Trapani J. The effectiveness of virtual simulation in improving student nurses' knowledge and performance during patient deterioration: A pre and posttest design. Nurse Education Today. 2018; 62: 128-133. PMid:29335162 https ://doi.or $\mathrm{g} / 10.1016 / \mathrm{j} . \mathrm{nedt} .2017 .12 .025$

[29] Bogossian F, Cooper S, Cant R, et al. Undergraduate nursing students' performance in recognising and responding to sudden patient deterioration in high psychological fidelity simulated environments: an Australian multi-centre study. Nurse Educator Today. 2014; 34(5): 691-6. PMid:24183634 https://doi.org/10.1016/j.nedt.2013.09 .015

[30] Chapelain P, Morineau T, Gautier C. Effects of communication on the performance of nursing students during the simulation of an emergency situation. Journal of Advanced Nursing. 2015; 71(11): 26502660. PMid:26189933 https://doi.org/10.1111/jan.12733 